\title{
AN UNUSUAL CASE OF INTESTINAL OBSTRUCTION CAUSED BY MESODIVERTICULAR BAND AND MECKELS DIVERTICULUM
}

\author{
Rajashekar S. Patil ${ }^{1}$, Hareesh Belagali², Vishal Kadeli ${ }^{3}$
}

\section{HOW TO CITE THIS ARTICLE:}

Rajashekar S. Patil, Hareesh Belagali, Vishal Kadeli. "An Unusual Case Of Intestinal Obstruction Caused By Mesodiverticular Band And Meckels Diverticulum". Journal of Evolution of Medical and Dental Sciences 2014; Vol. 3, Issue 12, March 24; Page: 3180-3184, DOI: 10.14260/jemds/2014/2263

ABSTRACT: Meckels diverticulum is a persistent remnant of the omphalomesenteric duct. It presents the most common congenital anomaly of the small intestine (1-4\%). Common complications related to a Meckel's diverticulum include hemorrhage, intestinal obstruction, and inflammation. Small bowel obstruction due to mesodiverticular band of Meckel's diverticulum is a rare complication. Herein, we report the diagnosis and management of a small bowel obstruction occurring due to mesodiverticular band of a Meckel's diverticulum.

KEYWORDS: Mesodiverticular band; Meckels diverticulum, Intestinal obstruction.

INTRODUCTION: Meckel's diverticulum is the most common congenital anomaly of the gastrointestinal system.1,2 It originates from failure of the vitelline duct to obliterate completely, which is usually located on the antimesenteric border of the ileum. Its incidence is between $1 \%$ and 3\%.3, 4, 5 Meckel's diverticulum occurs with equal frequency in both sexes, but symptoms from complications are more common in male patients. Most of the Meckel's diverticula are discovered incidentally during a surgical procedure performed for other reasons. In symptomatic patients, a variety of presentation have been reported, including Hemorrhage, inflammation, intestinal obstruction, hernial involvement (littre hernia), umbilicus sinus or fistula and tumours ${ }^{6,7}$. Histologically, heterotopic gastric and pancreatic mucosa are frequently observed in the diverticula of symptomatic patients ${ }^{1,2}$. Involvement of the mesodiverticular band of the diverticulum is seen rarely.

CASE REPORT: A 24-year-old male got admitted to the emergency service of our hospital with severe abdominal pain and distension and vomiting one day prior to admission, with no history of previous abdominal surgery. On examining the abdomen there was distention and guarding present, and bowel sounds were absent. He was non-febrile. No masses were palpable. There was no significant medical history. Laboratory findings showed a leukocyte count of $8900 / \mathrm{mm} 3$, whereas the hemoglobin and platelet values were $11.4 \mathrm{~g} / \mathrm{dl}$ and $216,000 / \mathrm{mm} 3$, respectively. All other studies, including electrolytes and urinalysis, were within normal limits. Erect abdominal film showed multiple air fluid levels on the film. On erect x-ray and USG it was diagnosed with mechanical intestinal obstruction, and nasal decompression and catheterization was done. Emergency exploratory laparotomy was performed under general anesthesia.

The distal part of the ileum was found to be markedly compressed by the mesodiverticular band within an area $70 \mathrm{~cm}$ proximal to the end of the ileum (Figure 1). Ileal loops were dilated proximal to the obstruction. Obstruction was caused by trapping of a bowel loop by a mesodiverticular band. After separating the Mesodiverticular band, the ileal loop was released and 
Meckels diverticulum was found gangrenous and adherent to the proximal ileum (Figure 2). On separation of the adhesions perforated ileum was seen proximally from the diverticulum (Figure 3).

Resection of the Meckel's diverticulum and functional end-to-end anastomosis of the bowel were performed. The perforation was closed primarily (Figure 4). The patient recovered without any complications and was discharged after seven days of hospitalization and was followed up after three weeks and was doing fine.

The diverticulum was confirmed as Necrosed Meckel's diverticulum by histological examination.

DISCUSSION: Meckel's diverticulum was originally described by Fabricius Hildanus in 1598. However, it is named after Johann Friedrich Meckel, who established its embryonic origin in 18098. Meckel's diverticulum is the most common congenital anomaly of the small intestine, with a prevalence of approximately 1-3\%, and is a true diverticulum containing all layers of the bowel wall, $3,5,9$. The average length of a Meckel's diverticulum is $3 \mathrm{~cm}$, with $90 \%$ ranging between $1 \mathrm{~cm}$ and $10 \mathrm{~cm}$. This diverticulum is usually found within $100 \mathrm{~cm}$ of the ileocaecal valve on the antimesenteric border of the ileum. The mean distance from the ileocaecal valve seems to vary with age, and the average distance for children under 2 years of age is known to be $34 \mathrm{~cm}$. For adults, the average distance of the Meckel's diverticulum from the ileocaecal valve is $67 \mathrm{~cm} .{ }^{4}$ Most cases that have Meckel's diverticulum are asymptomatic. Estimated risk for developing lifetime complications of the Meckel's diverticulum is around $4 \% .3,5,9$

Most of the patients are asymptomatic, and the diagnosis is difficult to confirm preoperatively. Among the symptomatic patients, two types of heterotopic mucosa (gastric and pancreatic) are found histologically within the diverticula. The frequent complications of Meckel's diverticulum are hemorrhage, intestinal obstruction, and diverticulitis. Intestinal obstruction is the second most common complication of Meckel's diverticulum. ${ }^{2}$

The clinical manifestation of complicating Meckel's diverticulum are frequently non-specific and can mimic other pathological conditions such as appendicitis, crohn's disease, cholecystitis, and peptic ulcer. 10

Symptoms are most frequent during childhood and the frequency decreases with age. ${ }^{11}$ Elsayes et al. ${ }^{1}$ noted that bowel obstruction accounts for up to $40 \%$ of symptomatic Meckel's diverticula. There are lots of mechanisms for bowel obstruction arising from a Meckel's diverticulum. Obstruction can be caused by trapping of a bowel loop by a mesodiverticular band, a volvulus of the diverticulum around a mesodiverticular band, and intussusception, as well as by an extension into a hernia sac (Littre's hernia).1, 2

Unusual cases include mechanical obstruction related to peritoneal or mesodiverticular band, ${ }^{12}$ long Meckel's diverticulum encircling small bowel loops, ${ }^{13,14}$ gall stones at neck of diverticulum, ${ }^{15}$, ${ }^{16}$ axial torsion of diverticulum around its narrow base. ${ }^{17}$ Similarly, as in our case, obstruction can be caused by trapping of a bowel loop by a mesodiverticular band. The important aspect of our case is clear demonstration of the mesodiverticular band of a Meckel's diverticulum.

The preoperative diagnosis of Meckel's diverticulum is often difficult, with only $6-12 \%$ of Being diagnosed correctly. ${ }^{18}$ Various imaging modalities have been used for diagnosing Meckel's diverticulum. Conventional radiographic examination is of limited value.19 Although of limited value, sonography has been used for the investigation of Meckel's diverticulum. High-resolution sonography 
usually shows a fluid-filled structure in the right lower quadrant having the appearance of a blindending, thick-walled loop of bowel. On computed tomography (CT), Meckel's diverticulum is difficult to distinguish from normal small bowel in uncomplicated cases. However, a blind-ending fluid or gasfilled structure in continuity with small bowel may be revealed. Abdominal CT is used for complicated cases such as intussusceptions. CT can help to confirm the presence of intussusception and distinguish between lead point and nonlead point intussusceptions. ${ }^{20,21}$

Among the asymptomatic patients, whether all incidental Meckel's diverticula should be resected or not is an unresolved question. On the other hand, for the symptomatic patients, treatment should always include resection of the diverticulum or the segment of the bowel affected by the pathology. ${ }^{3,8}$

Surgical treatment of a Meckel's diverticulum generally consists of diverticulectomy, either by simple excision in the transverse axis of the ileum to avoid luminal stenosis, or by resection of the adjacent ileal wall or a segment of ileum with anastomosis. The latter is reserved for patients with complicated diverticula. ${ }^{8}$

In conclusion, although Meckel's diverticulum is the most prevalent congenital abnormality of the gastrointestinal tract, it is often difficult to diagnose. Complicated Meckel's diverticulum is very uncommon cause of small bowel obstruction.

The complications of Meckel's diverticulum should be kept in mind in the differential diagnosis of small bowel obstruction.

\section{REFERENCES:}

1. K. M. Elsayes, C. O. Menias, H. J. Harvin, and I. R. Francis. Imaging manifestations of Meckel's diverticulum. American Journal of Roentgenology, vol. 189, no. 1, pp. 81-88, 2007.

2. O. Karatepe, C. Dural, C. Erçetin, G. Çitlak, A. Samaslioğlu, O. B. Gülçiçek, and S. Karahan. Rare complication of Meckel's diverticulum: loop formation of diverticulum. Turkish Journal of Medical Sciences, vol. 38, no. 1, pp. 91-93, 2008.

3. G. Dutta, A. S. Chowdhury, and M. Panda. Band of cacophony-abdominal catastrophe caused by the fibrous band of Meckel's diverticulum: a case report. Cases Journal, vol. 2, no. 7, article 7160, 2009.

4. J. Dumper, S. Mackenzie, P. Mitchell, F. Sutherland, M. L. Quan, and D. Mew. Complications of Meckel's diverticula in adults. Canadian Journal of Surgery, vol. 49, no. 5, pp. 353-357, 2006.

5. Tekin and T. Küçükkartallar. Meckel Divertikülü'nün Nadir Bir Komplikasyonu: Ileus. Firat Tip Dergisi, vol. 1, pp. 62-64, 2008.

6. Cullen JJ, Kelly KA. Current management of Meckel's diverticulum. Advances in Surgery 1996; 20: 207-214.

7. Arnold JF, pellicane JV. Meckel's diverticulum: a ten year experience. American Journal Surg 1997; 3:354-355.

8. K. W. Chan. Perforation of Meckel's diverticulum caused by a chicken bone: a case report. Journal of Medical Case Reports, vol. 3, article 48, 2009.

9. Sarioglu-Buke, N. Corduk, U. Koltuksuz, M. Karabul, B. Savran, S. Bagci. An uncommon variant of Meckel's diverticulum. Canadian Journal of Surgery, vol. 51, no. 2, pp. E46-E47, 2008.

10. Bronen RA, Glick S, Teplick S. Meckel's diverticulum: axial volvulus mimicking emphysematous cholecystitis. American Journal Gastroentrology 1984; 79: 183-185. 
11. Soltero MJ, Bill AH. The natural history of Meckel's diverticulum and its relation to incidental removal. A study of 202 cases of diseased Meckel's diverticulum found in King County, Washington, over a 15 year period. American Journal Surg 1976; 132: 168-173.

12. Vork JC, Kristenson IB. Meckels diverticulum and intestinal obstruction- report of a fatal case. Forensic SCI INT 2003; 138: 114-5.

13. Sciacca P, Borello M, Cellitti M, et al. Intestinal obstruction due to Meckel's diverticulum. Description of three cases. Minerva Chir 1998; 53(10): 795-9.

14. Murakami R, Sugizaki KI, Kobayashi Y. Strangulation of small bowel due to Meckel's diverticulum: CT findings. Clin image 1999; 23: 181-183.

15. Nakamoto T, Saga T, Fujishiro S, et al. Gall stone ileus with impaction at the neck of a Meckel's Diverticulum. Br J Radiol 1998; 71: 1320-1322.

16. Macari M, Panicek DM. Case report: CT findings in acute necrotizing Meckel's diverticulum due to obstructing enterolith. JCAT 1995; 19:808-810.

17. Malhotra S, Roth D, Gouge T, et al. Gangrene of Meckel's diverticulum secondary to axial torsion: a rare complication. AJG 1998; 93(8): 1373-75.

18. Sanders LE. Laparoscopic treatment of Meckels Diverticulum. Obstruction and bleeding managed with minimal morbidity. Surg Endosc 1995; 9: 724-7.

19. Ghahremani GG. Radiology of Meckels Diverticulum. CRC Crit Rev Diag Imaging 1986; 26:1-43.

20. A. Malik, Shams-ul-Bari, K. A. Wani, A. R. Khaja. Meckel's diverticulum-revisited. Saudi Journal of Gastroenterology, vol. 16, no. 1, pp. 3-7, 2010.

21. T. H. Lee, J.-O. Kim, J.-O. Kim. A case of intussuscepted Meckel's diverticulum. World Journal of Gastroenterology, vol. 15, no. 40, pp. 5109-5111, 2009.

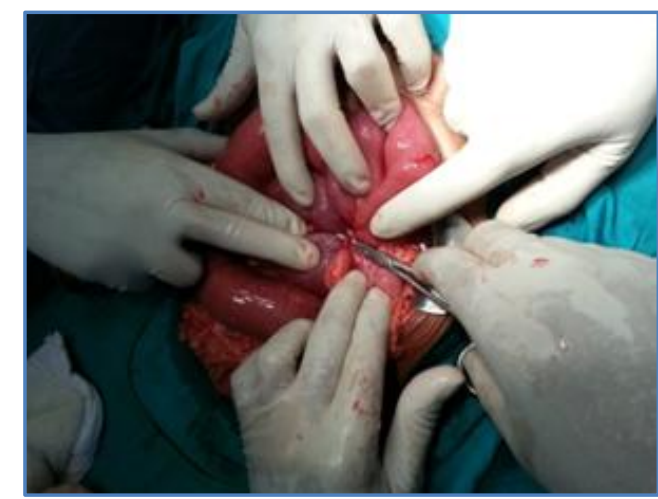

Fig. 1: Showing mesodiverticular band

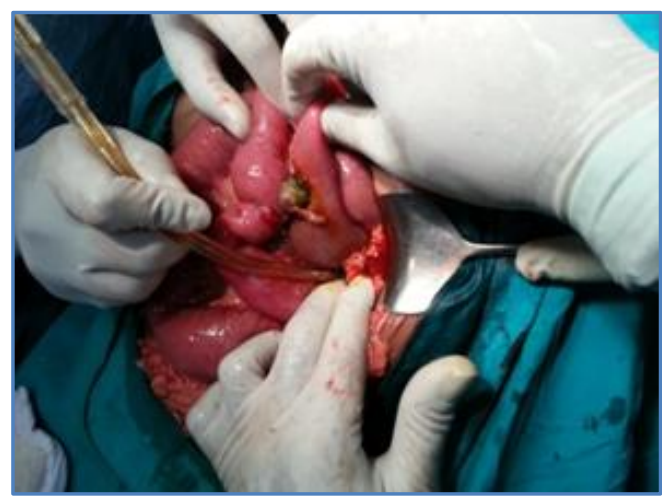

Fig. 2: Meckels diverticulum adherent to the proximal ileum 


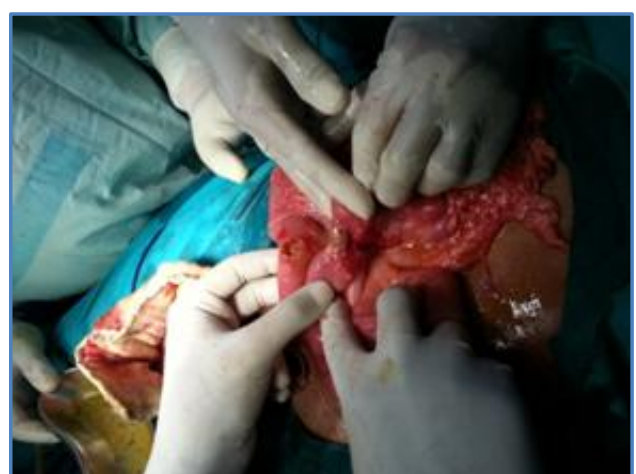

Fig. 3: Shows Meckels Diverticulum and perforated ileum

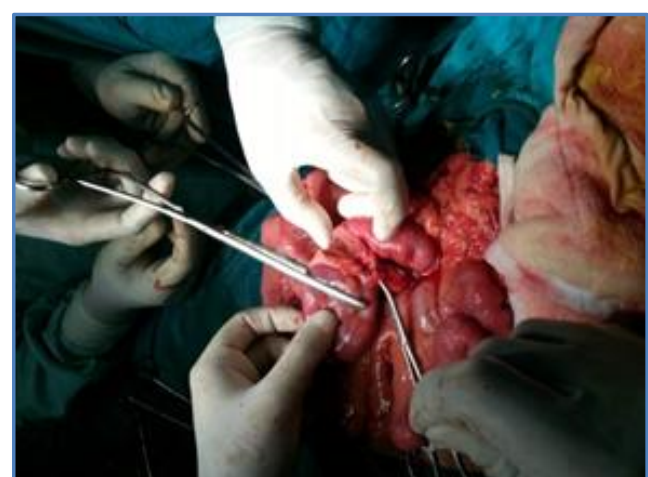

Fig. 4: Meckel's diverticulum end-to-end anastomosis was performed

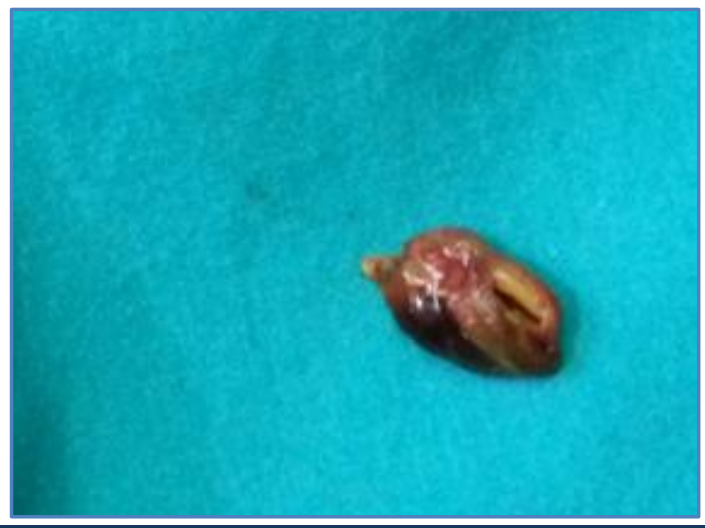

Fig. 5: Shows gangrenous Meckels Diverticulum

\section{AUTHORS:}

1. Rajashekar S. Patil

2. Hareesh Belagali

3. Vishal Kadel

\section{PARTICULARS OF CONTRIBUTORS:}

1. Associate Professor, Department of General Surgery, MRMC and Basweshwar Teaching Hospital, Gulbarga.

2. Resident, Department of General Surgery, MRMC and Basweshwar Teaching Hospital, Gulbarga.

3. Resident, Department of General Surgery, MRMC and Basweshwar Teaching Hospital, Gulbarga.

\section{NAME ADDRESS EMAIL ID OF THE CORRESPONDING AUTHOR: \\ Dr. Rajashekar Patil, Block No.56, Swastik Nagar, Bilgundi Layout, Sedan Road, Gulbarga - 585105. \\ E-mail: drrjsp@gmail.com}

Date of Submission: 24/02/2014. Date of Peer Review: 25/02/2014. Date of Acceptance: 05/03/2014. Date of Publishing: 24/03/2014. 